\title{
SUPPORTING DATA
}

\section{Cytotoxic Flavanones of Schizolaena hystrix from the Madagascar}

\section{Rainforest}

Brian T. Murphy, Shugeng Cao, Andrew Norris, James S. Miller, Fidisoa Ratovoson,

Rabodo Andriantsiferana, Vincent E. Rasamison, and David G. I. Kingston

Department of Chemistry, M/C 0212, Virginia Polytechnic Institute and State University,

Blacksburg, VA 24061-0212, Missouri Botanical Garden, P.O. Box 299, St. Louis

Missouri 63166-0299, and Centre National d'Application et Recherches

Pharmaceutiques, B.P 702, Antananarivo 101, Madagascar.

1. Structures of all isolated compounds.

2. ${ }^{1} \mathrm{H}$ NMR spectra of compounds 1 - 3 


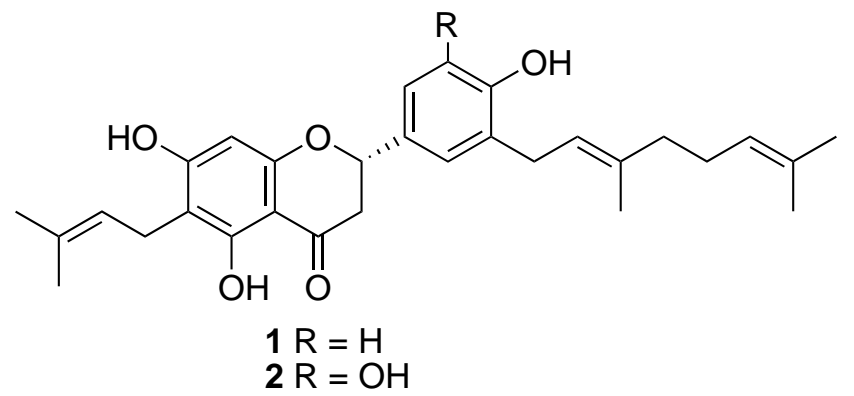<smiles>CC(C)=CCC/C(C)=C/Cc1c(O)cc2c(c1O)C(=O)CC(c1ccc(O)c(O)c1)O2</smiles>

Nymphaeol A

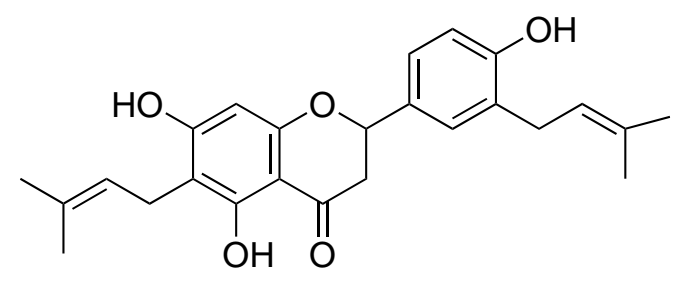

Macarangaflavanone B<smiles>COc1ccc([C@@H]2CC(=O)c3c(cc(O)c(C/C=C(\C)CCC=C(C)C)c3O)O2)cc1</smiles><smiles>CC(C)=CCC/C(C)=C/Cc1c(O)cc2c(c1O)C(=O)CC(c1ccc(O)cc1)O2</smiles>

Bonannione A<smiles>CC(C)=CCC/C(C)=C/Cc1c(O)cc2c(c1O)C(=O)[C@H](O)[C@H](c1ccc(O)cc1)O2</smiles>

Bonanniol A 


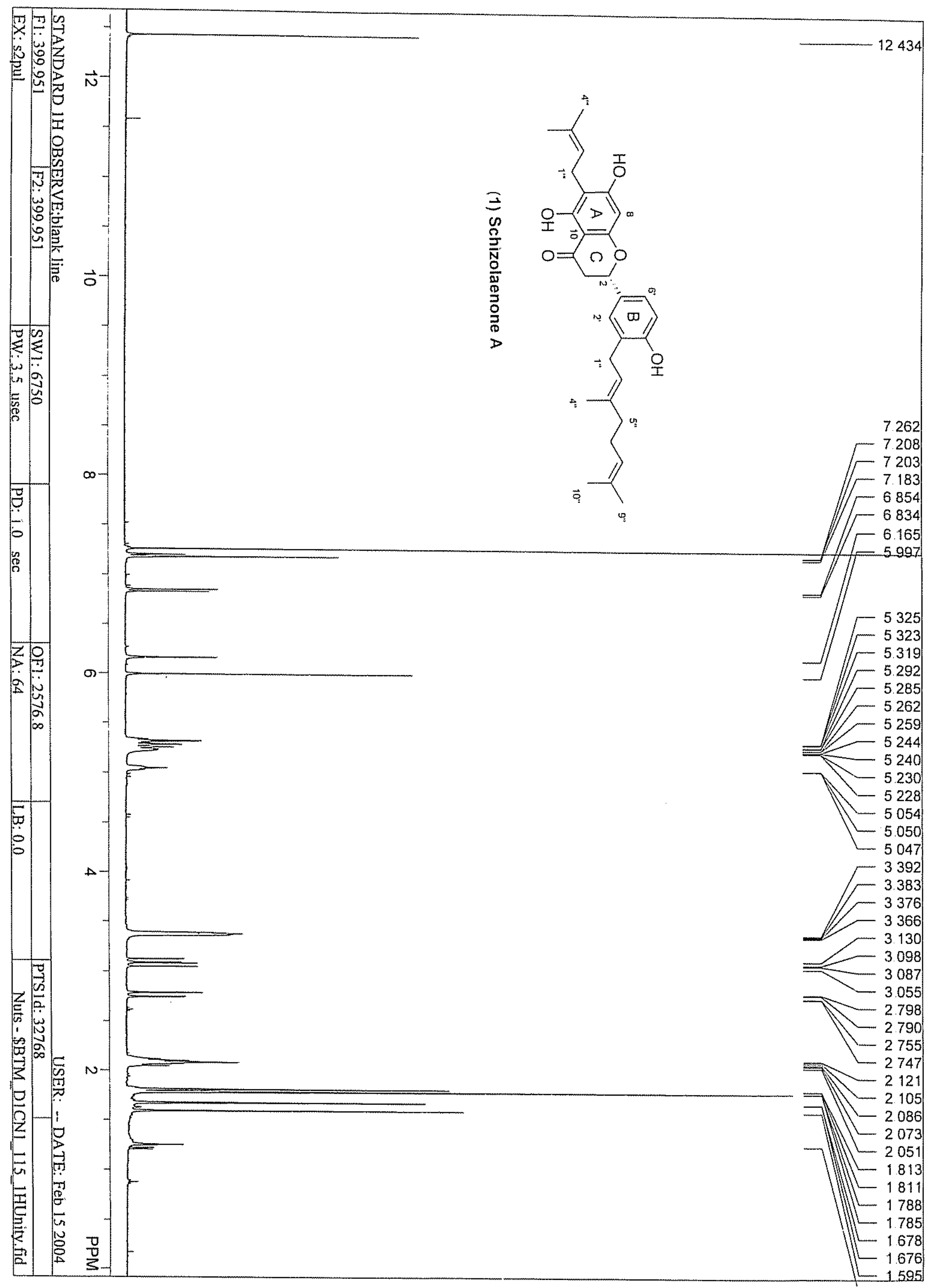




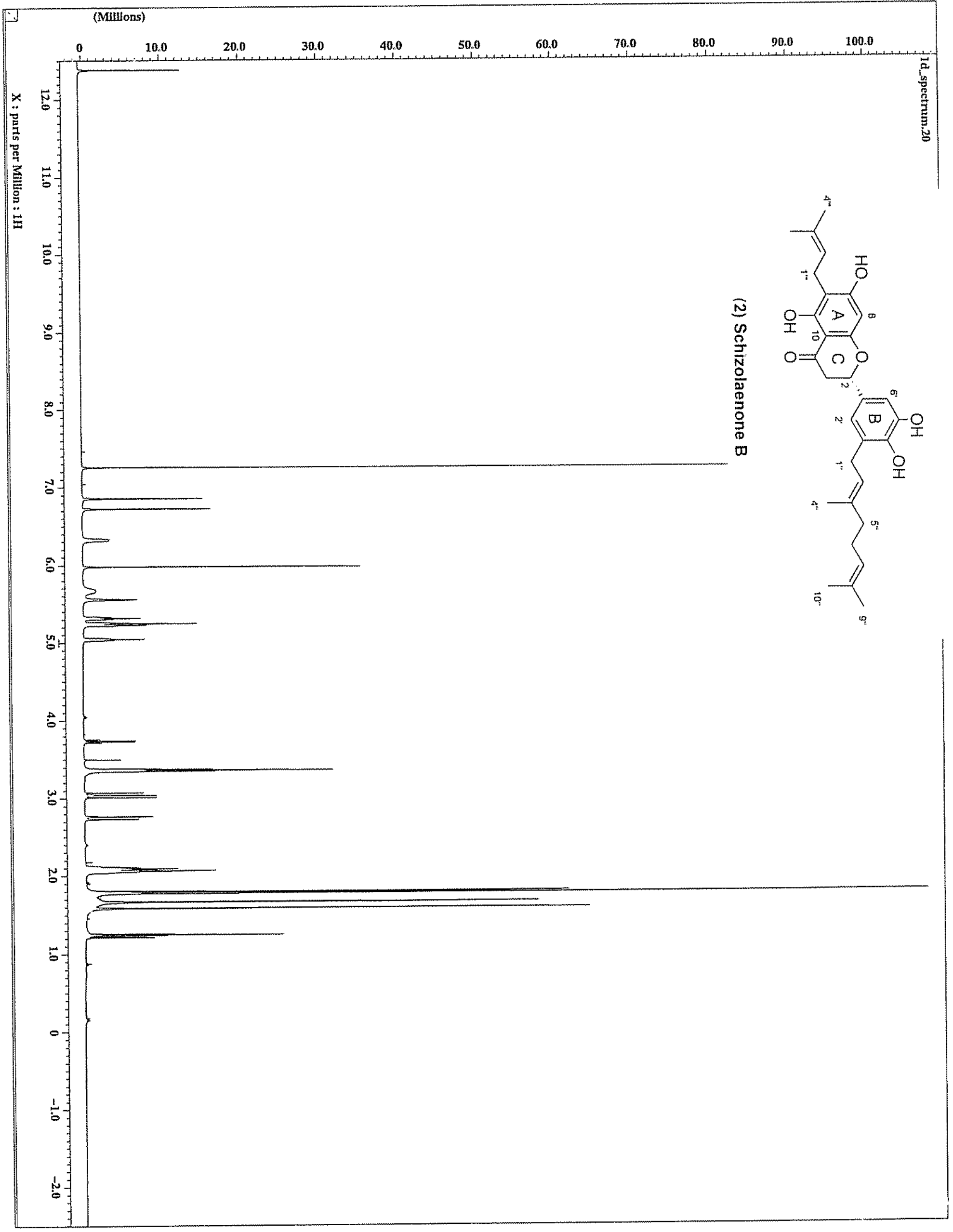




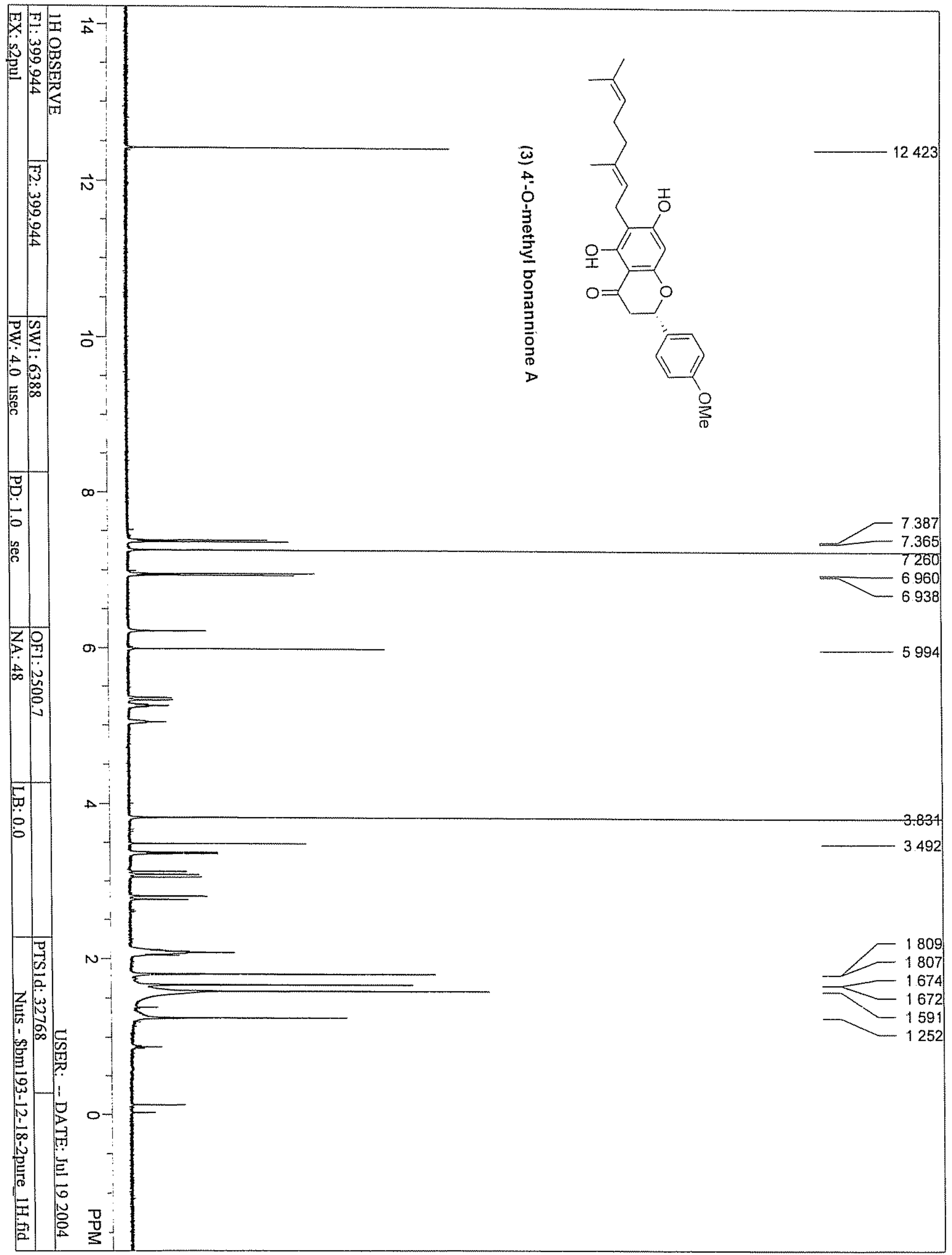

